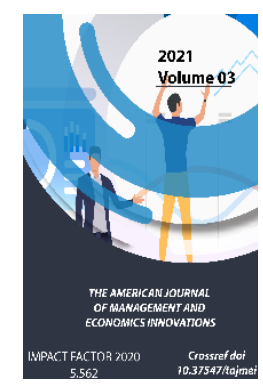

\title{
On Some Methods Of Economic Risk Management: Essence And Classifications
}

Journal Website:

http://theamericanjour

nals.com/index.php/taj

mei

Copyright: Original

content from this work

may be used under the

terms of the creative

commons attributes

4.0 licence.

\author{
Narbekov D.E. \\ Candidate Of Economical Sciences, Associate Professor, Tashkent Institute Of Finance, \\ Uzbekistan
}

\section{ABSTRACT}

The article notes that economic risk is one of the most multifaceted phenomena, the nature and components of which are not subject to a simple and unambiguous interpretation. But it should be noted that the classification of risks of this type, taking into account the many factors containing its signs is a rather voluminous problem due to the lack of a generally accepted systemic classification. The author argues that the above classification of methods for managing economic risks makes it possible to determine the characteristics used in their classification in the management process as a whole.

\section{KEYWORDS}

Hazard, phenomenon, risk exposure, risk factors, risk parameters, economic risk, economic risk parameters, classification signs of economic risk management, classification of economic risk management

methods.

\section{INTRODUCTION}

Economic risk is one of the most multifaceted phenomena, the nature and components of which are not subject to a simple and unambiguous interpretation. By now it is customary to understand economic risk as a phenomenon characterized by uncertainty (unknown) of results in the future, the likelihood of negative (positive) performance results.

In this context, the classification of economic risks, accounting for many factors containing its signs, types and subspecies is a rather 
voluminous and complex problem due to the lack of an established and generally accepted, as well as an exhaustive systemic classification of risks. In this case, the classification of risks serves as the basis for the definition and identification, assessment and technology of minimizing economic risk.

At the same time, it is necessary to take into account an important methodological feature - a large number of various manifestations of economic risk in practice contribute to the fact that the same type of risk is designated by different terms. Note that, analyzing the array of real financial and economic situations, it is very difficult to distinguish between individual types of risk due to their diversity and interrelationships.

\section{THE MAIN FINDINGS AND RESULTS}

A distinctive feature of both statistical and simple net risks is that in most cases they are associated with losses for activities or no losses (not profit). Among the reasons for net risks are natural disasters, accidents, etc. Speculative risks (dynamic) are associated not only with losses, but also with additional profits. The reasons leading to speculative risks include changes in the exchange rates of national currencies, changes in market conditions, changes in the conditions of investment activities, etc.

Therefore, it can be argued that economic risks can include not only those that directly lead to monetary losses, but also those that lead to losses of a non-economic nature, but they can also be measured in monetary terms.

The undesirability of the occurrence of damage determines the goal of economic risk management - to reduce losses associated with risk. That is why it is very important to choose the methods of economic risk management. This article proposes a classification of methods for managing economic risk, taking into account the peculiarities of economic risk as an object of management.

It can be seen from the definition of economic risk that the goal of managing economic risk can be achieved on the basis of managing its following parameters - the uncertainty of the occurrence of losses (a decrease in the frequency or probability of damage occurring $\rho$ ) and the amount of damage - $\rho$.

The joint values of these parameters of economic risk - the probability of damage $\rho$ and the amount of damage $\gamma$, describe the possible values of the magnitude of risk - low (small), medium (rather small), high (large) risk.

The undesirability of damage, which is permanently inherent in the very term of economic risk, the selected parameters characterizing its value, specify the goal and parameters of risk management as follows: the goal of management is to reduce damage in monetary terms and associated with the implementation of risk, and the main controllable risk parameters are $\rho, \gamma$. However, in order to determine which of these risk parameters really need to be improved, i.e. must become an object of control, it is necessary to analyze each of them separately to assess whether the value of this risk parameter is high, i.e. requiring its minimization, for example, at least to some acceptable level.

Since each of the risk parameters is influenced 
by different factors, it is necessary, firstly, among all possible factors to highlight the most priority ones and, secondly, to assess the impact of the latter on each of the risk parameters.

As practice shows, the most priority factors, called "structural characteristics of risk", can be attributed to $[1$, p. 160]:

Risk - a potential threat of damage caused by the specifics of the economic object, the characteristics of the risk situation and the nature of the damage itself. It is determined by the interaction of the risk bearer - an object or subject, and the environment in which the risk bearer lives and which, in turn, can provoke the risk realization;

Exposure to risk - a feature of the situation, characterized by the risk of damage;

Vulnerability - the degree of realization of the hazard, reflecting the intensity of damage;

Interaction with other risks is a factor reflecting the possibility of a particular risk being realized due to its connection or proximity to other risks.

In order to assess the impact of the above factors on the parameters of economic risk, i.e. structural characteristics of risk, it is necessary to collect, analyze and evaluate the database available for the specific risk.
The obtained results of the assessment make it possible to determine which of the parameters of an individual risk should become manageable and which management methods should be applied to them.

If the available risk database is incomplete, insufficient for the intended purposes, risk management methods should be used in relation to it under conditions of uncertainty.

Since the available risk database is a significant factor influencing the choice of one or another appropriate management method, it can be considered as the first sign of the classification of risk management methods (Fig. 1).

In conditions of sufficiency, the database on economic risk in relation to it can be applied management methods classified according to the attribute "controlled risk parameter" - the second attribute of the classification of risk management methods.

In accordance with the values of this attribute, control methods can be aimed at reducing the likelihood of damage $\rho$, as well as at reducing damage $\gamma$ (Fig. 1). 


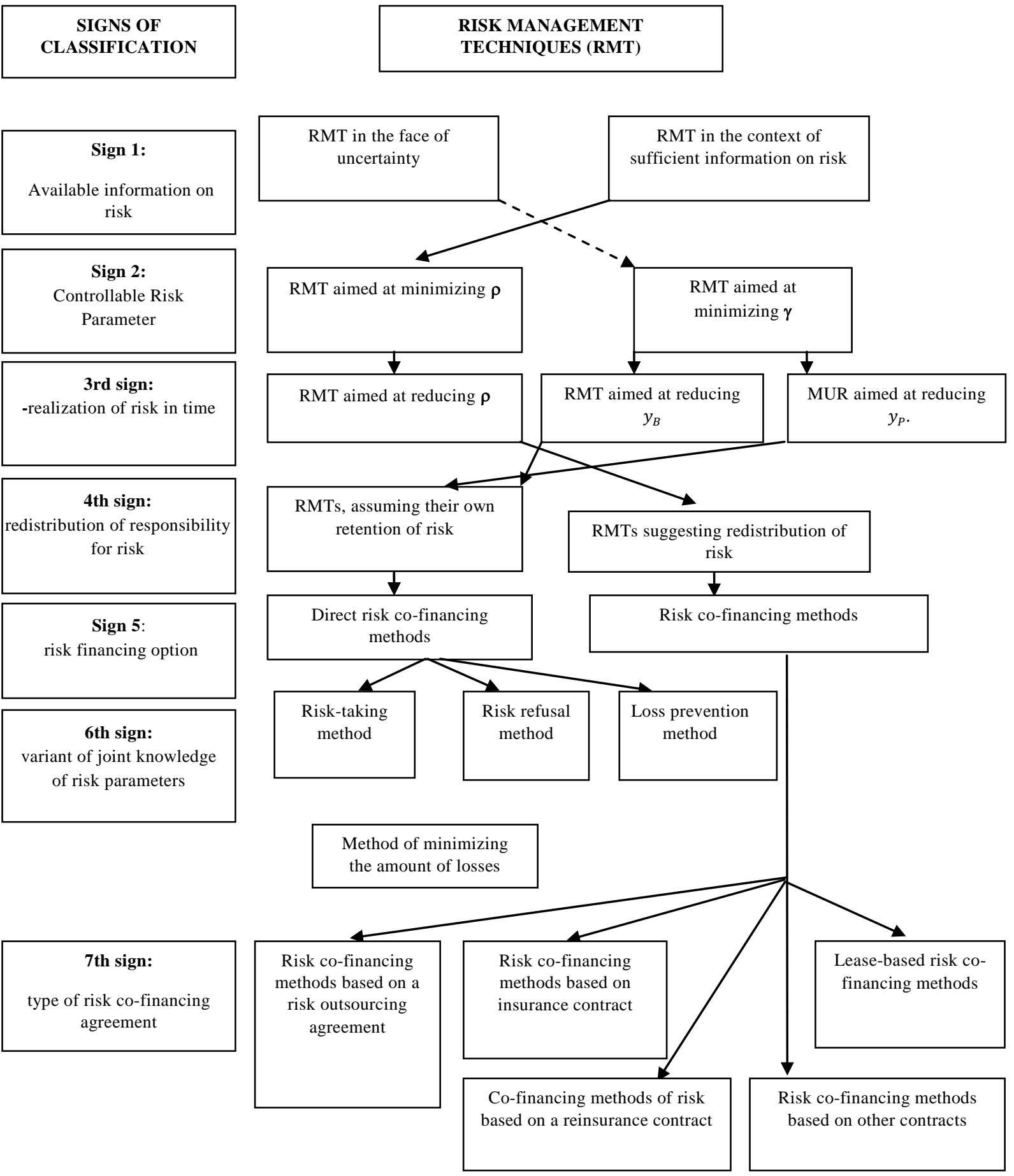

Fig. 1. Signs and methods of risk management and their relationship [2, p. 431]

It should be noted that the parameter of economic risk "amount of damage $\gamma$ ", as a controllable parameter, breaks down into two others - "possible damage $\boldsymbol{y}_{\boldsymbol{B}}$ " and "real damage $\boldsymbol{y}_{\boldsymbol{P}}$ ". The need for such a representation of such a risk parameter is due 
to the fact that the real value of damage becomes known after its occurrence, and possible damage can only be predicted before the actual damage occurs.

That is why the next sign of the classification of risk management methods, which would make it possible to separate the categories of "possible damage" and "real damage", is the sign of the realization of risk in time.

Taking this feature into account in risk management, classification methods can be divided into the following:

Methods of economic risk management aimed at reducing the likelihood of damage $\rho$;

Methods of economic risk management aimed at reducing the amount of possible damage $y_{B}$;

Methods of economic risk management aimed at reducing real damage $\boldsymbol{y}_{\boldsymbol{P}}$.

The need for independent consideration of a group of management methods aimed at minimizing possible damage and a group of methods aimed at minimizing real damage is due to the fact that the cumulative risk factors (its structural characteristics can have different effects on the predicted, possible value of damage $y$ and on its real value $\boldsymbol{y}_{\boldsymbol{P}}$.

In this case, the structural characteristic "interaction with systemic risks" can affect the amount of possible and real damage in different ways, if only because when assessing the expected damage, one variant of the interaction of the studied risk with other risks was taken into account, and when the risk is realized, when a real damage, interaction with other risks led, for example, to greater damage than envisaged at the forecast stage, when predicting possible damage.
So, in the case of direct financing of risks, it becomes possible to identify the following specific methods of risk management (Fig. 1);

A method of taking risks on oneself, used in the event that parameters $p, y_{\beta}$ and $y_{p}$ take acceptable values that allow the entity responsible for this risk to hold the risk. Its essence is the financing of losses at the expense of their own financial capabilities, for example, from the current income of the entity responsible for the entire risk;

A risk-aversion method (a risk-aversion method), used in the event that parameters $\mathbf{p}$, $y_{8}$ and $y_{p}$ take unacceptable values that do not make it possible not only for the entity responsible for this risk to hold the risk, but also to co-finance it;

A method of preventing losses, used in the event that the controlled parameter $\mathbf{p}$ is excessively high - the probability of the occurrence of damage. Its essence is the implementation of measures aimed at reducing the value of this parameter to an acceptable level so that in the event of a risk realization it is possible to cover the damage at the expense of the own financial capabilities of the subject responsible for the risk. An example is the replacement of old electrical equipment with new ones that reduce the likelihood of a fire. If, as a result of the redistribution of risk, it is completely transferred to a third party, for example, an insurance company, the latter, now responsible for all this risk, can carry out the corresponding measures on its own;

The method of reducing the amount of losses, used in the event that the controlled parameters $y_{\boldsymbol{B}}$ and $y_{p}$ are excessively high - the amount of possible and real damage. Its essence is the implementation of measures aimed at reducing the value of these parameters (individually or separately) to an 
acceptable level so that in the event of a risk realization it would be possible to cover real damage at the expense of the own financial capabilities of the entity responsible for the risk. As in the previous case, if a third party, for example, an insurance company, has assumed all responsibility for the risk, it can also take measures aimed at reducing the possible and real damage.

In this case, it should be noted that if both risk parameters require their improvement, they should become controllable variables, in relation to them, as already noted, the risk refusal method can be applied. However, in some cases, the entity responsible for the risk cannot refuse this risk. In this case, management methods are applied to each of the managed risk parameters:

The method of preventing losses is applied in relation to the high probability of the occurrence of damage $p$;

Method of reducing the amount of losses - to a high amount of possible damage $\mathbf{y}_{\mathbf{B}}$ and (or) real damage $y_{p}$.

Specification of risk management methods based on risk co-financing, in turn, is possible on the basis of the application of such a classification feature (seventh) as "type of risk co-financing agreement” (Fig. 1).

Examples of such methods include:

Method of risk co-financing based on a risk outsourcing agreement. Its essence is the transfer of risk to outsourcing in order to reduce possible losses associated with the realization of risk. So, the risk of investment activities of an insurance organization can be reduced due to the fact that it transfers part of the assets to outsourcing to a management investment company in order to receive a guaranteed investment income from their placement by an investment company. If the insurance company itself was engaged in investment activities in relation to these assets, it could receive losses from this in an amount much greater than is possible with outsourcing of its investment activities;

Method of risk co-financing based on an insurance contract. The essence of the method is the transfer by the bearer of the risk of the insurance company of liability (all or part of it) for a certain risk. If the risk materializes, the insurer will fully or partially cover the damage, i.e. participates in the co-financing of the risk;

Method of risk co-financing on the basis of a reinsurance agreement providing for the participation of a reinsurer in compensation for damage. The essence of the method is the transfer by the insurance company (bearer of the risk) to another insurance or reinsurance company of liability (all or part of it) for a certain risk it has accepted. If the risk is realized, the reinsurer is fully (or partially) involved in compensation for real damage, i.e. participates in the co-financing of the risk;

Method of risk co-financing based on a lease agreement. Its essence is the redistribution of liability for risk, according to which, upon the occurrence of real damage, each of the parties (the lessor and the lessee) participate in covering the damage, taking into account the redistribution of risk between them in accordance with the terms of the lease agreement;

Methods of risk co-financing based on other agreements.

Realization of economic risk is associated with a possible or real loss, so the answer to the question of who can and how will compensate it is very significant (Fig. 2). In this case, the solution to this issue is primarily determined by the distribution of risk liability among the following entities: 
Subject $-\mathrm{C}_{\mathrm{A}}$, who is a risk bearer and bears responsibility for it, for example, a driver who is speeding on roads is a risk bearer and is responsible for its implementtation;

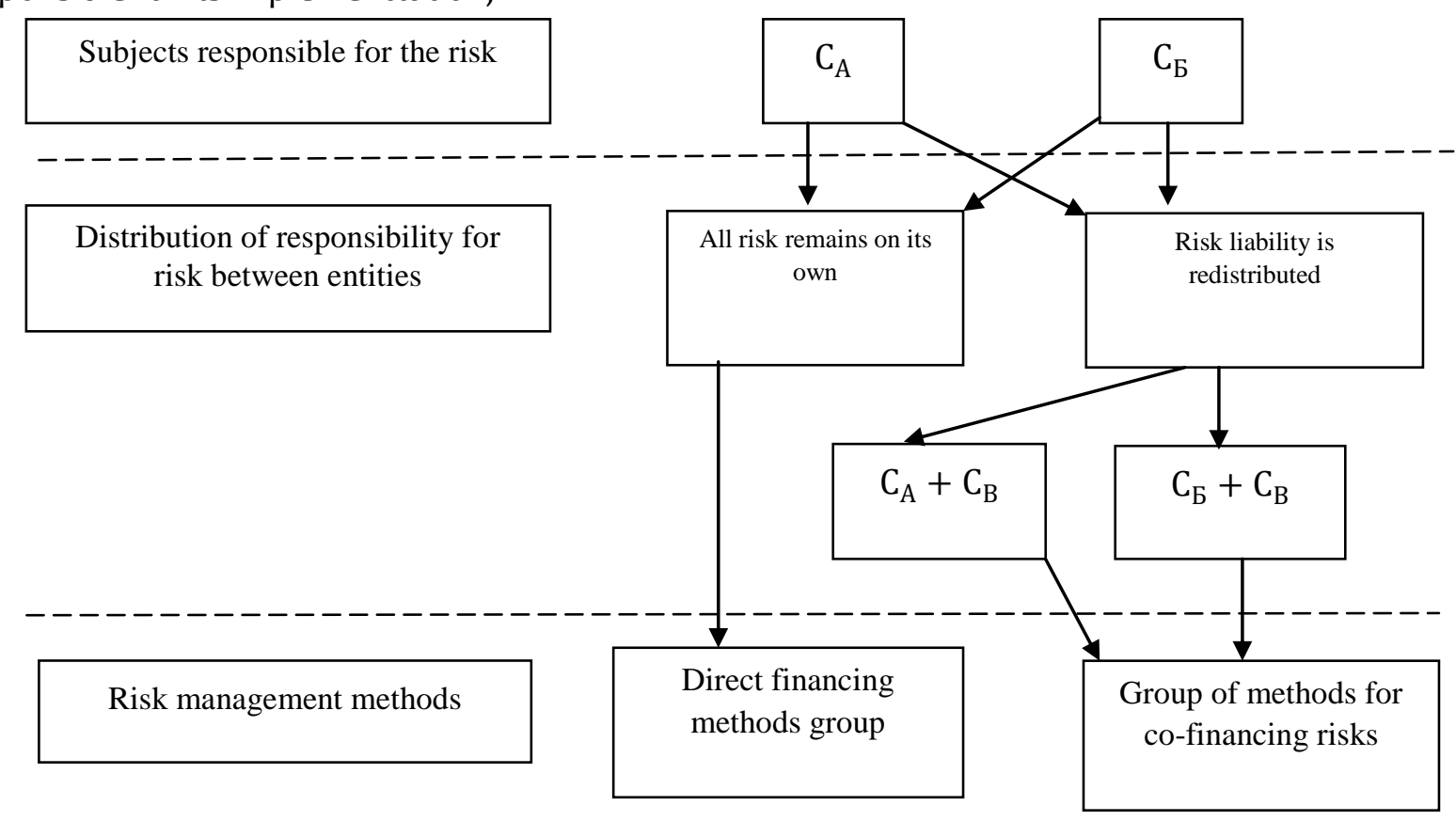

Fig. 2. Methods of risk management due to risk redistribution [2, p. 431]

Subject $-\mathrm{C}_{\mathrm{B}}$, which is responsible for the risk, but is not its bearer, for example, the state is responsible for the risks associated with the use of atomic energy, but the direct bearers of these risks are the entities directly working at the NPP;

Subject $-C_{B}$, which is not a risk bearer, but responsibility for it has been transferred to him, for example, an insurance organization that, under an insurance contract, has assumed responsibility for the risk of an accident of a citizen S.T. Rasulov who is a bearer of this risk.

Subjects $C_{A}, C_{B}$, who are initially responsible for the risk, can leave all responsibility for it on their own, and on the contrary, they can transfer it. In this case, responsibility can be transferred partially or completely to third parties -
Subjects $\mathrm{C}_{\mathrm{B}}$, who accept it on agreed terms. For example, S.T. Rasulov, when concluding an accident insurance contract, can transfer his responsibility for this risk in full.

In this case, the insurance contract does not contain a clause on the deductible - on the participation of S.T. Rasulov in compensation for damage. He may also transfer liability for this risk to the insurer in part.

"Redistribution of responsibility for risk" can be considered as the fourth sign of the classification of risk management methods. Its use is justified by the fact that the redistribution of risk liability affects the risk financing option.

Since compensation for damage comes at the expense of the subject, who is fully or partially responsible for the risk, one can distinguish between: 
- Methods of direct financing of risks, assuming:

First, full retention of the risk by the subject responsible for it;

Secondly, risk financing at the expense of this entity.

- Methods of risk co-financing, implying redistribution of responsibility for risk, partial responsibility for the risk of each of the subjects involved in the redistribution of risk, participation of each of the subjects in financing the risk, taking into account the accepted share of responsibility for it.

It should be noted that among the subjects participating in co-financing, there may also be those that have nothing to do with risk liability and its redistribution, but, as a rule, partly and on a voluntary basis participate in compensation for real damage. This cofinancing can take the form of sponsorship or donations from entities.

Direct financing of risk is responsible for all responsibility for the risk, which is left at the own retention of the entity, and is carried out at the expense of its financial resources. Risk co-financing is responsible for the share of risk liability assumed by the entity, and is carried out at the expense of the financial capabilities of the same entity.

Examples of direct risk financing are:

Coverage by the citizen himself of all expenses caused by an accident that happened to him, from which he was not insured;
Coverage of all expenses by the insurance company related to the accident of the insured citizen;

Coverage of all costs associated with an environmental disaster by the state;

Coverage of all expenses related to the fire by the sponsor (s).

Examples of risk co-financing are:

Full or partial coverage by the insurance company of the expenses related to the accident of the insured citizen (in addition, sponsorship and donations may be included in the coverage of expenses);

Partial state coverage of the costs associated with the provision of new housing to victims of the flood (in addition, both victims and sponsors can participate in covering the costs);

Partial coverage by the state and sponsors of the costs associated with the provision of new housing to flood victims;

Participation of insurance companies and the state in covering the costs associated with loss of crops due to drought (in addition, both victims and sponsors can participate in covering costs).

"Risk financing option" can be considered as the fifth indicator of the classification of risk management methods. Therefore, risk management methods that meet different risk financing options are subdivided into a group of direct risk financing methods and a group of risk co-financing methods (Fig. 3 ).

It is necessary that within each of these groups further classification of risk management methods is also possible. 
Stage 1. Risk identification

Stage 2. Analysis of the available risk database with the aim of assessing the impact on the risk parameters $\mathrm{p}, \mathrm{y}_{\mathrm{B}}, \mathrm{y}_{\mathrm{P}}$ of risk factors - its structural characteristics

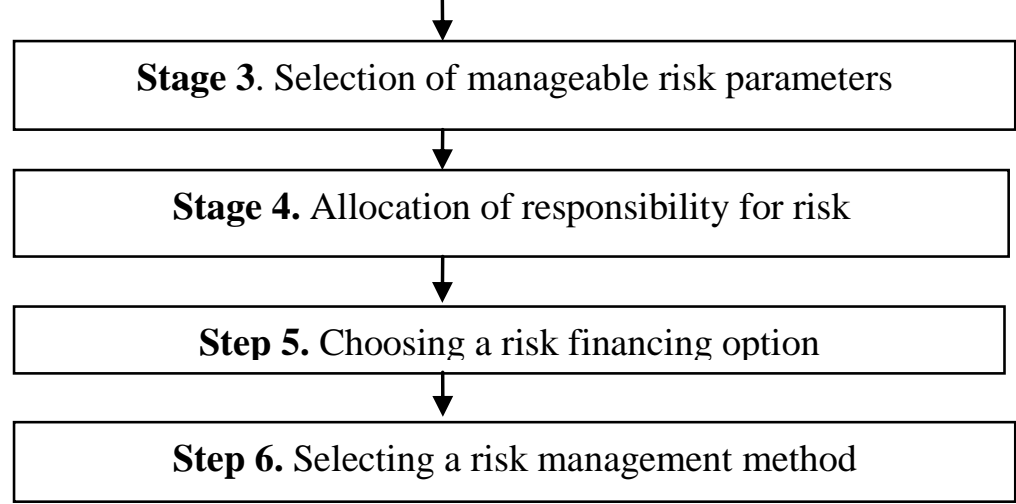

Fig. 3. Flowchart for choosing a risk management method

Specification of risk management methods based on direct financing of risk is possible based on the use of such a classification criterion as a variant of joint values of risk parameters.

In general, the procedure for selecting a risk management method can be described by a sequence of certain stages and implemented in accordance with the block diagram.

\section{CONCLUSIONS AND RECOMMENDATIONS}

The essence of economic risk as an uncertain possibility of damage, measured in monetary terms, determined the following set of possible manageable risk parameters - the probability of damage $p$, possible damage $\boldsymbol{y}_{\boldsymbol{B}}$ and real damage $y_{p}$. The purpose of these parameters is significantly influenced by certain factors - the so-called structural characteristics of risk.

All risk management methods applied in relation to the controlled parameters can be divided into groups corresponding to the options for redistributing responsibility for risk and financing it.

In conclusion, it should be noted that, in general, taking into account the characteristics of economic risk and justified selection of features makes it possible to classify risk management methods, which is used when implementing the proposed procedure for selecting a management method that meets the risk under study as a whole. 


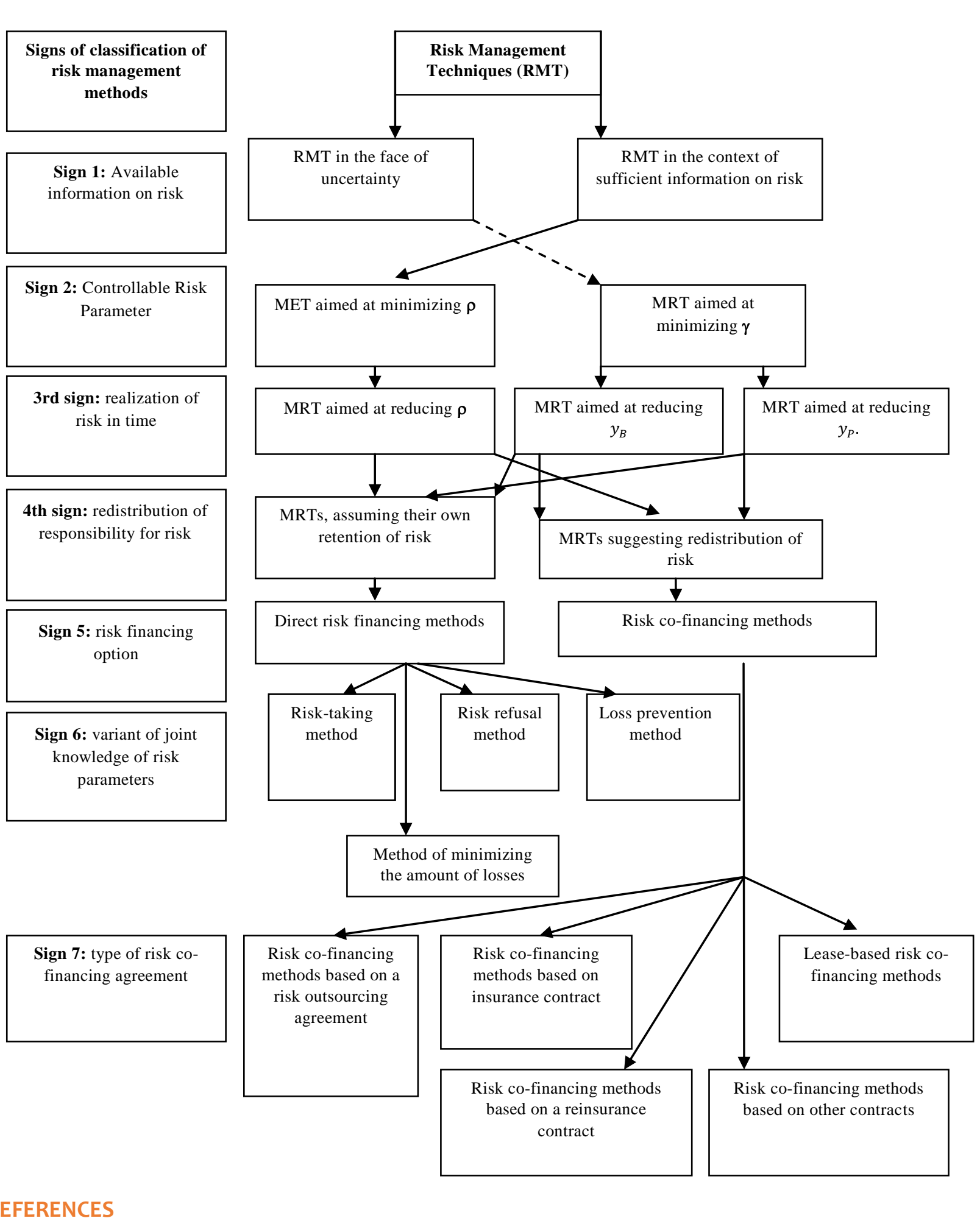

\section{REFERENCES}

1. Chernova G.V., Kudryavtsev A.A. (2005) Risk management: Textbook. Allowance. Moscow: TK Welby, Prospect Publishing House. - p. 160. (Чернова рисками: учеб. пособие. - М.: ТК Велби, Изд-во Проспект, 2005. - 160 с.) 
2. Decision-making theory in 2 volumes. Volume 2: textbook and workshop for undergraduate and graduate programs. G. Khalin [and others]; executive editor V. G. Khalin. - Moscow: Yurayt Publishing House. 2019. - p. 431. (Теория принятия решений в 2 т. Том 2: учебник и практикум для бакалавриата и

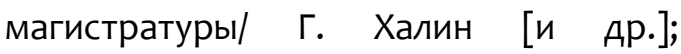
ответственный редактор В. Г. Халин. Москва: Издательство Юрайт, 2019431c.)

3. Lutfullaevich, Y. G. (2020). RISK ANALYSIS OF FOREIGN DIRECT INVESTMENTS IN INNOVATIVE PROJECTS: CASE OF UZBEKISTAN. Asia Pacific Journal of Business Review, 5(1), 11-19.

4. Allayarov, Sh. PhD; Mirzamakhmudov, M.; and Mirzamakhmudova, M. (2020) "ANALYSIS OF REGULATORY SANDBOX IN THE NETHERLANDS THAT PROMOTE DEVELOPMENT OF INNOVATIVE FINTECH STARTUPS"// International Finance and Accounting: Vol. 2020 : Iss. 3 , Article 34. Available at: https://uzjournals.edu.uz/interfinance/vol 2020/iss3/34

5. Allayarov, Sh., Allayarov S., Yuldasheva U., Madjidov N. (2020) Assessment of the effectiveness of the results of the fiscal policy of the republic of Uzbekistan// International Journal of Advanced Science and Technology Vol. 29, No. 7, (2020), pp. 7920-7926.

6. Yoziev, G. L. (2021). Conceptual approaches to building a perspective model of national innovation systems: Lessons for Uzbekistan. South Asian Journal of Marketing \& Management Research, 11(3), 46-52. 